\title{
Weather and Climate Research in Taiwan: Potential Application of GPS/MET Data
}

\author{
Chun-Chieh $\mathrm{Wu}^{1,{ }^{*}}$, Hung-Chi Kuo ${ }^{1}$, Huang-Hsiung $\mathrm{Hsu}^{1}$ and Ben Jong-Dao Jou ${ }^{1}$
}

(Manuscript received 8 July 1999, in final form 2 March 2000)

\begin{abstract}
Meteorological research in Taiwan mainly includes the East Asian climate, the heavy rainfall system (Mei-Yu front) and the typhoon research. In addition to these research components, an operational center on numerical weather prediction is actively run at the Central Weather Bureau. There are strong collaborations between Taiwan and the international meteorology communities. The COSMIC program in Taiwan is a new Taiwan-U.S. joint program designed to launch eight low-earth-orbiting satellites in 2004 for GPS/MET soundings.

Accurate profiles of temperature and water vapor in the troposphere are essential for the meteorological research in Taiwan. Low-level moisture convergence is important for the maintenance of the monsoon system. Moisture convergence also plays an important role in the formation and maintenance of the heavy rainfall events in the Mei-Yu frontal system. For an accurate typhoon track and intensity prediction, an accurate analysis of atmospheric flow field as well as an accurate representation of heating profile in the typhoon model is required. This means better data on the wind, the temperature and, in particular, the moisture field are needed for improved research. With the potential for providing temperature and moisture information at high vertical resolution, the GPS/MET technique may make a significant contribution to meteorological studies in Taiwan.

The GPS/MET soundings available from COSMIC provide an excellent opportunity for meteorological research in Taiwan. Preparation work has to be done in Taiwan to take a full advantage of GPS/MET data associated with the launching of COSMIC. A powerful computing facility is required to meet the time constraint for the operational data assimilation in numerical weather prediction (NWP). Procedures for the reception, distribution and archiving of the GPS/MET data, the procedures for quality control of the data flow, as well as the $3 D$ and 4D-variational data assimilation
\end{abstract}

\footnotetext{
${ }^{1}$ Department of Atmospheric Sciences, National Taiwan University, Taipei, Taiwan, ROC

* Corresponding author address: Dr. Chun-Chieh Wu, Department of Atmospheric Sciences, National Taiwan University, 61, Ln. 144, Sec. 4, Keelung Rd., Taipei 10772, Taiwan, ROC

E-mail: cwu@typhoon.as.ntu.edu.tw
} 
systems for assimilation of GPS/MET data on both regional and global scales, need to be developed at the Central Weather Bureau. The assimilation schemes should also incorporate the GPS/MET data with other types of remote sensing observations, as well as other conventional observations. The observational and background error covariances need to be developed. It is also important to assess the impact of GPS/MET data on the NWP and to demonstrate the added value relative to other data sets. Carefully designed assimilation experiments need to be performed to verify the usefulness of GPS/MET soundings. It is intriguing to conduct a field experiment during the Mei-Yu or typhoon season to validate the GPS/MET soundings during the initial in-orbit operations of COSMIC. Finally, it is crucial to set up a well-equipped COSMIC data center in Taiwan.

(Key words: COSMIC, GPS/MET, East Asian climate, Heavy rainfall system, Typhoon, 3DVAR, and 4DVAR)

\section{INTRODUCTION}

COSMIC (Constellation Observing System for Meteorology, Ionosphere and Climate) is a collaborative U.S.-Taiwan science experiment to demonstrate the utility of atmospheric limb soundings from a constellation of low-earth orbiting (LEO) satellites in operational weather prediction, space weather monitoring, and climate monitoring and research. This project is jointly undertaken by the National Space Program Office (NSPO) in Taiwan and the University Corporation for Atmospheric Research (UCAR) in the U.S., in collaboration with the Jet Propulsion Laboratory (JPL), and with the participation of many governmental, academic and private institutions in both Taiwan and the U.S.

As shown in Kuo et al. (1998), the scientific and operational goals of COSMIC are to (a) improve global and regional weather forecasting; (b) improve global space weather monitoring and forecasting; (c) provide datasets for climate and global change research; and (d) advance earth gravity field knowledge. In order to reach these ambitious goals, the scientific requirements and milestones need to be defined and specified in greater detail. To maximize the benefit of COSMIC to meteorological studies in Taiwan, the potential use of the GPS/ MET data has to be carefully examined, and preparation work has to be done before the actual launching of the COSMIC satellites.

Meteorological research in Taiwan mainly includes the heavy rainfall system during the Mei-Yu season (typically in May and June), the typhoon, and the East Asian climate research. Typhoons and heavy rainfall systems are the most serious and threatening weather events among all natural disasters in Taiwan. Because of the lack of data over the vast Pacific ocean and the strong interaction between the typhoon circulation and the rainfall system with the mesoscale Central Mountain Range (CMR), making good forecasts of these systems in the vicinity of Taiwan is highly challenging.

On the other hand, as Taiwan is situated at the boundary of the Eurasian continent and the 
Pacific, and also in the subtropical region where tropical-extratropical interaction occurs vigorously, weather and climate in Taiwan are undoubtedly influenced by the East Asian monsoon. Complex topography and land-sea contrast in this region are the two major factors shaping the variability of the East Asian climate and monsoon. As such, studies have been conducted actively in Taiwan on the complicated variability of short-term climate in East Asia.

As a review paper in the special issue on COSMIC, in section 2 the background of GPS/ MET is reviewed. The current understanding of research and forecasting issues related to the heavy rainfall system, typhoons and East Asian climate in Taiwan are reviewed in sections 3, 4 and 5, respectively. The related research activities, data requirements, and the potential use of GPS/MET are also presented. In section 6, some important issues regarding the application of the GPS/MET data to meteorological research in Taiwan are discussed.

\section{REVIEW OF GPS/MET BACKGROUND}

The application of the GPS for active measurement of the Earth's atmosphere has been intensively investigated in the recent years (see an overview from Businger et al., 1996). The sensitivity of atmosphere refractivity to the presence of water vapor makes it possible for the ground-based GPS receivers to provide continuous data on integrated water vapor above the receiver site. If the position of the receiver is accurately known and the ionospheric delay has been accounted for, an estimation of the vertically integrated water vapor overlying the receiver can be derived from the GPS signals and observations of surface temperature and pressure (e.g., Rocken et al., 1995). Integrated water vapor represents the total latent heat available in the column, and has the potential to provide powerful constraints to NWP models (Kuo et al., 1996) and in weather analysis.

Meanwhile, with the launch of a GPS receiver on a LEO satellite on 3 April 1995 (i.e., an experiment called GPS/MET; Ware et al., 1996), temperature soundings can be obtained using the radio occultation technique. Ware et al. (1996) showed that accurate vertical temperature profiles may be obtained using the GPS limb sounding technique from approximately $40 \mathrm{~km}$ to about $5-7 \mathrm{~km}$ in altitude where moisture effects are negligible. However, above $40 \mathrm{~km}$ and below $5 \mathrm{~km}$, the temperature retrievals show some difficulties. Sharp temperature inversion characteristics of the tropopause with a vertical resolution approaching that of radiosonde soundings can also be identified. Besides, in principle, humidity profiles can be obtained from the refractive profiles wherever the temperature distribution is known from other sources, such as radiosondes, or over tropical regions where horizontal and temporal variations in the temperature are small and reasonably well represented in global weather prediction models.

Recent work by Kuo et al. (1998) has also shown that high quality GPS/MET radio occultation data can be obtained even when the occultation goes through a sharp temperature gradient associated with an upper-level front. The results again indicate that GPS/MET soundings have the potential for observing important weather systems near the tropopause over data void regions in a global analysis.

In addition, the assimilation of refractivity observations from a hypothetical GPS/MET 
constellation through an observing system simulation experiment (OSSE) on the ERICA (Experiment on Rapidly Intensifying Cyclones over the Atlantic) IOP 4 rapid cyclogenesis event (Kuo et al., 1997) demonstrated an improved analysis of moisture, temperature and wind fields, as well as the short-range prediction of a marine cyclone by $13 \mathrm{hPa}$ in $48 \mathrm{~h}$. It was also shown that the low-level GPS/MET data are important for the prediction of cyclones.

It has been proposed by Eyre (1994) and shown by Zou et al. $(1999,2000)$ that the GPS/ MET refraction angle data can be directly assimilated into a NWP model. As a single LEO GPS receiver can observe more than 500 occultations per day, with roughly uniform global coverage, this method promises to provide valuable measurements of refractivity, which can be useful in weather forecasting, especially when the complete GPS/MET observation operator can be used in 3D and 4D-variational data assimilation systems (3DVAR; 4DVAR).

In summary, with operationally available datasets, integrated water vapor data from earthbased receivers and refractivity profiles from spaced (LEO) receivers represent a potentially important new resource for operational NWP, and have the potential to enhance the analysis and prediction of weather and climate (also see Anthes et al, 2000 for a thorough review). Nevertheless, it should be noted that the GPS/MET data are "indirect" synoptic-scale meteorological observations, which need to be retrieved or assimilated. The greatest strength of the data are the accurate temperature and height measurement in the upper troposphere. Yet the usefulness in the lower troposphere (particularly water vapor retrieval in the lower troposphere) has not been fully demonstrated. More research is needed to evaluate this potential in detail and to develop capabilities to obtain maximum benefit from these new sources of atmospheric data.

\section{HEAVY RAINFALL RESEARCH IN TAIWAN}

\subsection{Background}

Mei-Yu period in Taiwan, i.e., May and June, is a season with transitions. During this season, the cold air mass from Siberia is weakening and the warm air mass from the tropics is strengthening. The boundary of these two air masses frequently forms a quasi-stationary front (i.e., Mei-Yu front) in the subtropical area, extending from the south of Japan to Taiwan and southern China. The major characteristics of the front are weak temperature gradient (low baroclinicity as compared to the typical mid-latitude frontal system) and strong moisture gradient and wind shear across the front (Chen and Chang 1980). Accompanying this quasistationary front, a wide cloud band embedded within organized mesoscale convective systems (MCSs) is commonly observed from satellite imageries (e.g., Fig. I). These MCSs often lead to heavy rainfall and severe flooding in localized areas. Pronounced geographic and diurnal variation of the heavy rainfall events around the island is also evident (Chen 1992). The occurrence of heavy rainfall events in the Mei-Yu season shows a primary peak in the early afternoon and a secondary peak in the early morning (Chen and Yang 1988). In terms of location, there is a maximum in Chia-Yi and Mountain $\mathrm{A}-\mathrm{Li}$ areas and a secondary maximum in Tao-Yuan, Hsin-Chu, and Miao-Li regions (Fig. 2).

Many observational and numerical studies (Trier et al., 1990; Chen et al., 1991; Johnson 


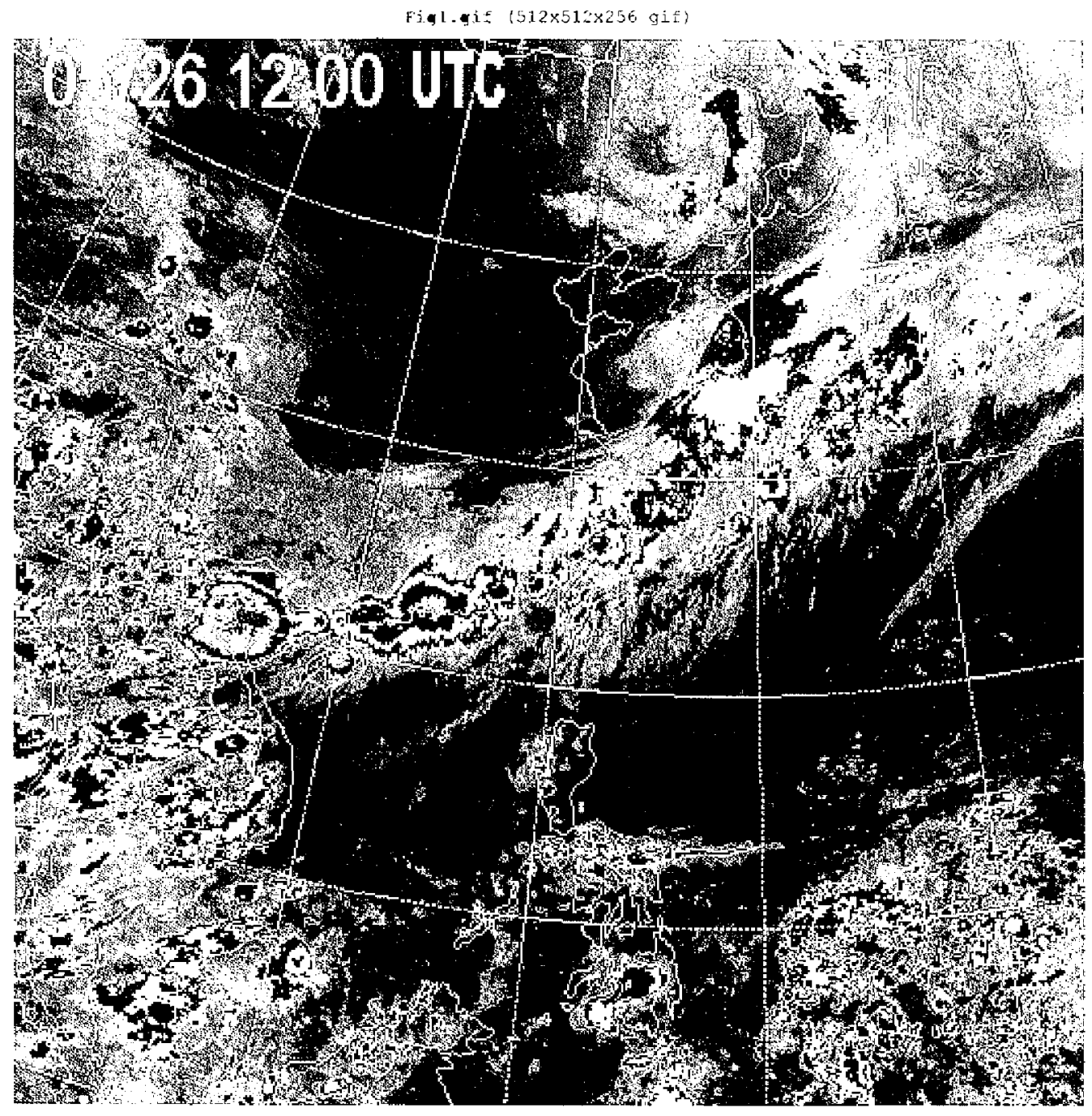

Fig. 1. Enhanced GMS V satellite picture at 1200 UTC 26 May 1999. This satellite image illustrates a Mei-Yu front extending from Japan to south China. Accompanying convective systems are vividly shown. This frontal system brought heavy rainfall to coastal and mountainous areas over the island of Taiwan.

and Bresch 1991; Sun et al., 1991; Chen and Liang 1992; Jou and Deng 1992; Lin et al., 1992; Lin 1993; Hsu and Sun 1994; Chen and Li 1995; Yu et al., 1999) have shown the frontal system is often affected by the presence of Taiwan terrain, and that the pre-frontal low-level wind maximum (low-level jet: LLJ) produces many interesting mesoscale weather phenomena along the coast and over the island. In addition, the land-sea contrast coupled with island topography produces land-sea breeze, mesolow, and regional circulation, which are important 


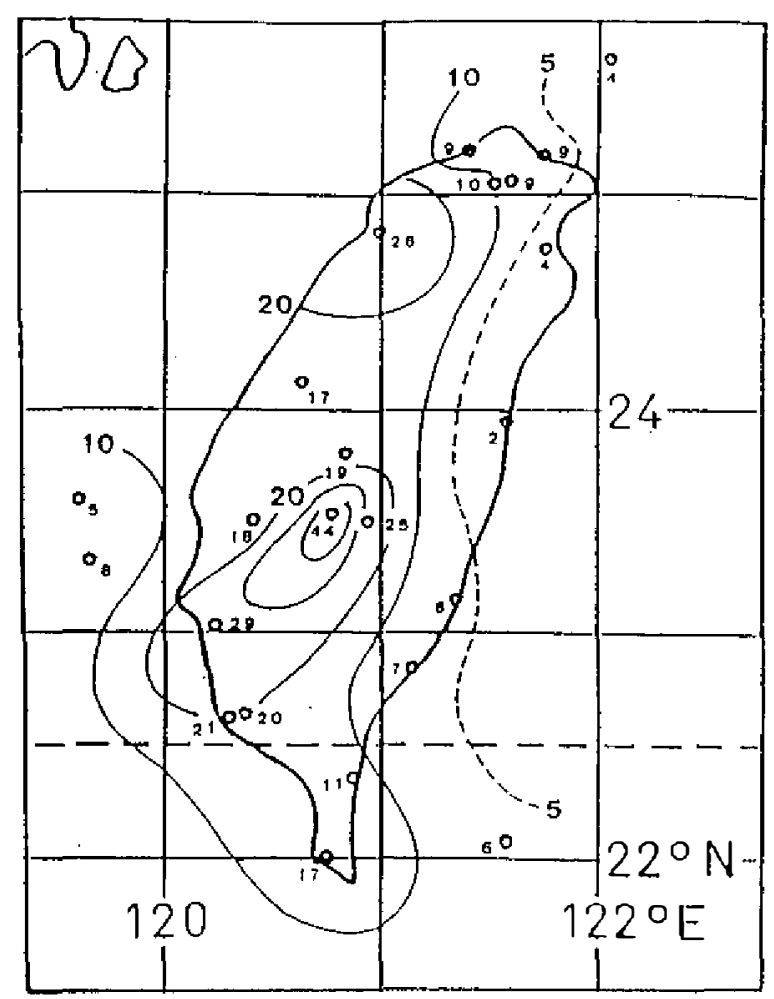

Fig. 2. Frequency distribution of heavy rainfall event $(>100$ $\mathrm{mm} \mathrm{day}^{-1}$ ) in Taiwan Mei-Yu season of May-June 19751984 (From Chen and Yang 1988).

in modulating the local precipitation distribution.

According to Trier et al. (1990), the inhomogeneous distribution of precipitation attending the frontal passage in the Taiwan Mei-Yu season is also closely related to strong regional variations in thermodynamic stability across the island. These variations in stability are linked to the mesoscale effects of terrain, and to the larger-scale influence of advection of an unstable tropical air mass into the region by a low-level wind maximum. Thus, adequate observations of the temperature and the moisture of the air mass upstream can provide important information for both the understanding and the forecasting of heavy rainfall events over the island.

To improve both the basic understanding and the forecast capability of the heavy rainfall systems in the Taiwan Mei-Yu season, a ten-year program, "Taiwan Area Mesoscale Experiment (TAMEX)," was executed from 1983 to 1992. Intensive observation data from sounding, surface, automatic rain gauge, conventional and Doppler radar networks have been extensively collected and analyzed. An overview of the TAMEX program and its scientific achievement can be found in Kuo and Chen (1990) and Chen (1992). The continuation of TAMEX has been conducted through the program "The Heavy Rainfall Research in Taiwan," starting from 1994 (Jou 1997). Several numerical simulations and data assimilation experiments on the heavy rainfall systems have also been performed (Jou et al., 1999).

As indicated in Jou (1997), heavy rainfall research in Taiwan after TAMEX has put more emphasis on the effect of Taiwan topography on the Mei-Yu front, the low-level jet, and the meso low. However, the lack of observational platforms over the oceanic area surrounding 
Taiwan and the lack of intensive observations over mainland China have impeded the progress in the investigation of the heavy rainfall system. Without this upstream information on the structure and the environmental factors of the Mei-Yu front, it is very difficult to understand the formation of MCS, the low-level jet, as well as the evolution of the Mei-Yu front. The forecast capability for heavy rainfall in the Taiwan Mei-Yu season is improved with TAMEX, but is still rather limited at the present time. The average threat score was about 0.2 with a threshold of $0.5-\mathrm{mm}$ daily rainfall. Moreover, the prefigurance was much lower than the post agreement, indicating a lack of understanding of the mesoscale processes and the highly complicated orographic influences on the mesoscale processes. Mei-Yu front and the associated mesoscale phenomena thus are important research topics in the Taiwan area.

\subsection{Potential application of GPS/MET data}

The GPS/MET soundings of temperature and water vapor in the free atmosphere may provide an additional important data source for future heavy rainfall study in Taiwan. Although the GPS/MET data are essentially on the synoptic scale and the usefulness in the lower troposphere (particularly water vapor retrieval in the lower troposphere) has not been fully demonstrated, yet the GPS/MET data over the oceanic area in East Asia may help to study the large-scale water vapor source for the Mei-Yu front and heavy rain events in Taiwan. The hydrological cycles during the Mei-Yu season can be better estimated, and therefore the capability for quantitative precipitation forecast (QPF) may also be evaluated. The collective effects of moist convection along the Mei-Yu front on the potential vorticity and ropopause dynamics (e.g., Davis and Emanuel 1991; Chang et al., 1998) can be studied with the high vertical-resolution GPS/MET data near the tropopause. With the establishment of the aroundthe-island Doppler radar network in Taiwan by the end of 2000, it is hoped that intensive observations from the Doppler radar network and the GPS/MET data can be incorporated into data assimilation in the numerical model. Therefore, better data can be obtained to improve our understanding on the dynamics and forecasting issue of heavy rainfall systems near Taiwan.

\section{TYPHOON RESEARCH IN TAIWAN}

\subsection{Background}

As indicated in Wu and Kuo (1999), typhoons are the most serious and threatening weather events among all natural disasters in Taiwan. On average, typhoons make landfall on Taiwan 3-4 times a year. The gusty wind and heavy precipitation associated with a typhoon affect weather in Taiwan significantly, even if it does not make landfall. Due to the presence of the high and complicated mesoscale topography associated with the CMR of Taiwan; significant variations in track and intensity of a typhoon may occur when it approaches the island. The existence of CMR also results in significant mesoscale variations in pressure, wind and precipitation distribution associated with typhoons over Taiwan.(Wang 1980; Chang 1982; Bender et al., 1987; Lin 1993; Yeh and Elsberry 1993a and 1993b; Shieh et al., 1996; Wu and Kuo 
1999).

Due to the lack of mesoscale observations, the three-dimensional dynamic and thermodynamic structures of a typhoon can not be properly described before, during, or after it passes Taiwan, thus make the forecasting of tropical cyclones near Taiwan an extremely difficult task. The understanding of typhoons landfalling in Taiwan, including the impact of Taiwan terrain on the dynamics of the typhoon circulation, and the forecasting of track, intensity and mesoscale wind and precipitation distribution are the most important scientific and forecasting problems for meteorologists in Taiwan. In view of the importance of typhoons to the lives and economy of Taiwan, the National Science Council of Taiwan launched a national project for disaster mitigation, under which an integrated program of both basic and applied research on typhoons was set up in 1997. A thorough review of the challenging issues and research foci associated with typhoons at landfall in Taiwan has been presented in Wu and Kuo (1999), i.e.,

1) Effects of topography on typhoon motion, mesoscale wind and precipitation distribution, on mesoscale structure of typhoons (in terms of pressure, wind, moisture, temperature and vorticity), and on the development of secondary vortices.

2) Mesoscale convective systems embedded within typhoons, their interaction with vortex circulation, and their impact on wind gusts and rainfall distribution, which are strongly modulated by the CMR.

3) The priorities for typhoon forecasts in Taiwan are listed as: 1. track forecast; 2 . intensity forecast; and 3. wind and precipitation forecast. To improve track forecast, the interaction between environmental flow and typhoons, and the impact of environmental flow on typhoon motion need to be better understood.

4) Data improvement: Improvements in the quantity and quality of data associated with typhoons are highly important to typhoon research and forecasting. Supplementary soundings during the period when a typhoon effects Taiwan, the set-up of an around-the-island Doppler radar network, an enhanced surface rain gauge network, an integrated sounding system, as well as the use of aerosondes (Holland et al., 1992), could all bring useful new data related to typhoons. To conduct a specific field experiment using modern mesoscale observation platforms (such as a research aircraft, an airborne Doppler radar, and a Doppler radar on wheel), to study the four-dimensional evolution of the storm as it approaches the CMR is a very high priority, and is being planned. Meanwhile, the strategy for adaptive observation (Emanuel and Langland 1998) near the Taiwan area also needs to be evaluated.

5) Study of the statistical and analog forecast method: Because the mesoscale precipitation distribution and the wind field distribution during typhoons effecting Taiwan are strongly modulated by the topography of Taiwan, the rainfall and wind field distribution could be forecasted reasonably well if a model could predict the position and intensity of a storm well. Therefore, the statistical and analog method could be very useful for forecasting the mesoscale wind and precipitation distribution. The accuracy and skill of the statistical and analog approaches has been carefully evaluated by the Central Weather Bureau (CWB) in Taiwan. Meanwhile, to have a reasonably good track prediction, a proper vortex specification and an accurate description of the environmental flow are very important, and these in 
turn require the assimilation of all available remote sensing observations (in particular, satellite data), and the use of advanced techniques (such as the four-dimensional variational data assimilation).

\subsection{Potential application of GPS/MET data}

As mentioned above, one of the greatest uncertainties involved in typhoon research and prediction in Taiwan is the lack of observational data inside and surrounding the storm. Using the Geophysical Fluid Dynamics Laboratory (GFDL) hurricane prediction system, Bender et al. (1997) showed the sensitivity of the track prediction to the initial analysis. Wu and Emanuel (1993) and Wu and Kurihara (1996) demonstrated the need of enhanced observation and accurate analysis and prediction in the upper troposphere in order to improve typhoon forecast, as well as the importance of accurate representation of heating (water vapor) profile in hurricane models (Fig. 3). The above results all indicate the need for better data on wind, temperature and moisture fields through the troposphere surrounding the storm area for improving our understanding on typhoons and their forecasts. With the high vertical resolution of GPS/MET data on temperature and moisture fields, there is great potential in making use of the GPS/ MET data to help typhoon research, possibly by employing of the concept of tropopause dynamics and potential vorticity dynamics (Wu and Emanuel 1995; Morgan and Nielsen-Gammon 1998). However, this potential will not be realized until further detailed exploration is undertaken.

Due to the limited amount of observations, and the very complicated impact of topography on typhoons, numerical models may be regarded as the best vehicle for improving our knowledge. However, better observations need to be provided to support the models. In
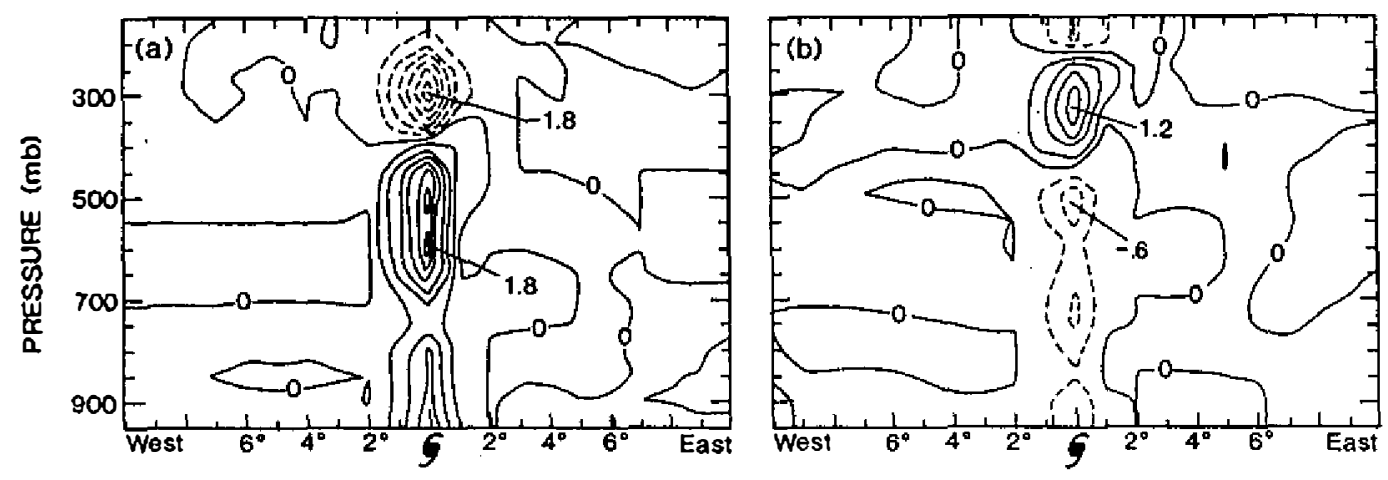

Fig. 3. West-east cross section of a 12-hour forecast of Hurricane Bob (1991) at 000UTC 18 August 1991 from GFDL hurricane model. The change of potential vorticity due to (a) condensational heating and (b) vertical advection are shown. Unit is PVU/12-hour, contour interval is 0.3 PVU/ 12-hour and negative values are indicated by dashed lines. Note that while the two effects compensate to some extent, there remains a net reduction of PV at upper levels and a net gain in mid- and low-levels. 
addition, our ability to simulate the detailed interaction and its associated mesoscale wind and precipitation features from numerical models is still far from satisfactory. It is hoped that better observations from the satellites (e.g., Merrill and Velden 1996), Doppler radars (Marks et al., 1992), reconnaissance (e.g., the impact from Omega Dropwindsonde, Franklin et al., 1996), unmanned aircrafts (Holland et al., 1992; Langford and Emanuel 1993), specific field experiments, as well as the GPS/MET data, can all be incorporated into high-resolution numerical models through advanced data assimilation techniques. Therefore, a systematic approach combining the observational analyses and the numerical model experiments will advance our understanding of the dynamics of mountain effects on typhoons, possibly aiding in the forecast and understanding of the storm behavior near Taiwan.

\section{EAST ASIAN CLIMATE RESEARCH IN TAIWAN}

\subsection{Background}

Taiwan is situated at the boundary of the Eurasian continent and the Pacific, as well as in the subtropical region where tropical-extratropical interaction is especially vigorous. Its weather and climate are undoubtedly influenced by the East Asian monsoon. Complex topography and the land-sea contrast in this region are the two major factors shaping the variability of the East Asian climate and monsoon. The high-rising, vast Tibetan plateau exerts its influence, thermally in summer and mechanistically in winter, not only on the large-scale circulation in Asia but also on the planetary-scale circulation. The nearby oceans, i.e., the Pacific and the Indian Ocean, also affect the variability of the Asian climate. In other words, the climate and monsoon in East Asia are the consequences of the interaction among three physical climate subsystems, i.e., ocean, atmosphere and land. The East Asian climate and monsoon are also part of the global climate system. Thus, research focusing on the East Asian monsoon can not ignore the effects of the global circulation.

In recent years, research efforts in Taiwan have been organized to better understand the short-term climate variability in East Asia, which involves multiple time scales varying from synoptic, intraseasonal, seasonal, to interannual scales. Four major research topics are emphasized: (1) variability of the East Asian monsoon; (2) effects of tropical-extratropical interaction on the East Asian climate; (3) effects of ocean-atmosphere interaction on the East Asian climate; (4) ensemble effects of atmospheric convection on the East Asian climate.

The organized research efforts have resulted in better understanding of the physical mechanisms affecting the East Asian Monsoon, e.g., the interannual variability of dry and wet MeiYu season (Wang et al., 1992; Wang and Hwu 1994; Hwu and Wang 1994; Pan and Wang 1996), the variability of South Asian anticyclone (Kau and Deng 1994), and the onset of East Asian summer monsoon (Lin and Lin 1997; Lu 1998; Chen and Wang 1998; Hsu et al., 1999).

Progress in numerical simulations has also been made. Various numerical models have been developed in recent years for both climate simulation and mechanistic studies. They include global barotropic, shallow-water, and baroclinic models, general circulation models such as NTUGCM (Kau et al., 1995; Kau 1998) and (Community Climate Model), and regional models such as PennState/NCAR mesoscale Model (MM5), Regional Spectral Model 
(RSM), and Purdue Regional Model (PRM). These models have been used to study various regional and global climatic phenomena.

Scientists in Taiwan have actively participated in several international field experiments and research programs, such as Tropical Ocean Global Atmosphere/Coupled Ocean and Atmosphere Response Experiment (TOGA/COARE), TOGA Tropical Atmosphere and Ocean (TAO), Tropical Rainfall Measuring Mission (TRMM), South China Sea Monsoon Experiment (SCSMEX), and Atmospheric Modeling Intercomparison Project (AMIP)

\subsection{Role of moisture in East Asian climate: Potential application of GPS/MET data}

\section{(1) Introduction}

Moisture is one of the most important variables for understanding the East Asian Climate, especially for the East Asian Summer Monsoon. Scale-interaction in both temporal and spatial scales is a significant factor affecting the East Asian monsoon. While progress has been made in understanding the dynamics of East Asian monsoon, the variability of moisture in all scales has not been well documented. Based on the products of 4-D data assimilation and satellite retrieval, we have only crude observations about the variability of moisture, especially in the boreal spring and summer.

\section{(2) Importance of moisture budget}

Differential heating between the land and ocean and the high-rising topography of South and East Asia lead to the occurrence of the most significant monsoon on Earth. The large differential heating is significantly enhanced by the latent heat release in deep convection, indicating the importance of moisture toward a better understanding of East Asian summer monsoon. More details are discussed as follows:

- Seasonal cycle and abrupt change

The lower troposphere in the Bay of Bengal contains much more moisture than the surrounding lands before May, but becomes drier after May when the moisture starts to accumulate in the Indochina-Malay land-bridge (Hsu et al., 1997). This change of moisture content is likely due to the moisture convergence associated with the switch of large-scale circulation from winter pattern to summer pattern (Fig. 4). Heavy precipitation also tends to occur in the area of low-level moisture convergence. Several hypotheses have been proposed on how the change of circulation, heating and moisture distribution described above corresponds to the onset of East Asian summer monsoon, and why it occur abruptly in a matter of days (Hsu at el. 1999). Yet the exact mechanism remains unclear. The role of moisture has to be considered to better understand such processes.

\section{- Interannual variability}

The East Asian summer monsoon exhibits significant interannual variability. For example, during a wet Mei-Yu year in Taiwan most of the moisture is carried into the monsoon region by the southwesterlies, while in the dry Mei-Yu year it is the southeasterlies that bring 
Specific humidity(vertically integrated)

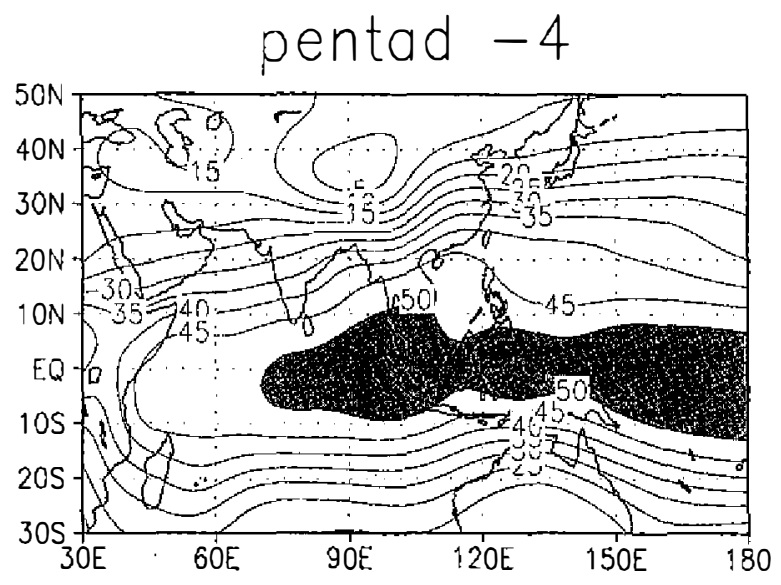

pentad 0

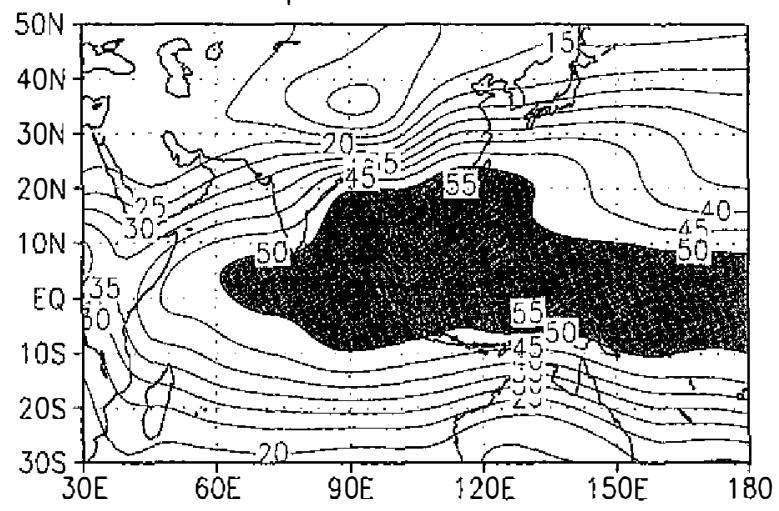

pentad +4

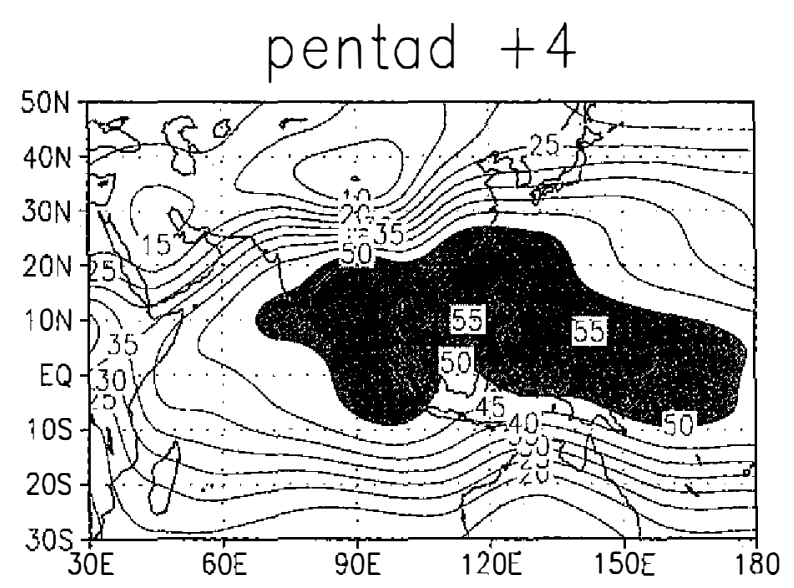

Fig. 4. Composites of vertically integrated specific humidity -4 pentad before (upper panel), during (middle panel), and 4 pentad after (lower panel) the first transition of Asian summer monsoon, based on the transition dates defined by $\mathrm{Hsu}$ et al. (1999). ECMWF reanalysis is used in calculation and contour interval is $5 \mathrm{kgm}^{-2}$. The evolution indicates a dramatic increase of moisture in South East Asia and South China Sea through the evolution. 
in most of the moisture. Another example is a recent study by researchers at the Climate Diagnostics Center: "During a normal onset (South China Sea monsoon) year, we find weak UTH (Upper Troposphere Humidity) anomalies throughout the global tropics. The early monsoon onset year of 1984 is characterized by strong negative UTH anomalies in the central equatorial Pacific and positive UTH anomalies in the Western Pacific." It is also known that during El Niño (La Niña) the total precipitable water anomalies are positive (negative) in the central/eastern equatorial Pacific, and are negative (positive) in Southeast Asia and the western Pacific. These examples indicate the importance of the moisture field in a better understanding of interannual variability of East Asian climate.

\section{- Intraseasonal variability}

Many studies propose that intraseasonal oscillation affects the active and break phases of Asian summer monsoon and may initiate the onset of East Asian summer monsoon (Fig. 5). Several numerical studies have suggested the important role of hydrological cycle (e.g., convection, moisture distribution, etc.) in sustaining the intraseasonal oscillation in boreal summer (e.g., Webster 1983; Lau and Peng 1990; Wang and Xie 1997; Krishnan and Venkatesan 1997). However, none of these hypotheses has been tested, mainly due to the lack of reliability in the observed hydrological cycle data (e.g., moisture distribution, surface evaporation, etc.). In other words, the role of moisture in the intraseasonal oscillation deserves further study based on more reliable moisture data.

- Sources and sinks

Tao and Chen (1987) proposed a schematic diagram of East Asian summer monsoon and suggested the importance of the cross-equatorial flow south of the South China Sea. Other studies, however, found that low-level moisture advection also occurs in the southwesterlies originating from the Indian Ocean, and in the southeasterlies originated from the southern flank of the Pacific subtropical anticyclone. Meanwhile, the role of the South China Sea as a moisture source is also a current research focus. Although recent reanalyses show weaker evaporation in the South China Sea than in the surrounding lands, the three reanalyses disagree with each other quantitatively. Clearly, that the relative contribution of the moisture convergence and local evaporation to the moisture budget and the hydrological cycle in the South China Sea has yet to be examined.

\section{(3) Potential application of GPS/MET data}

Water vapor content and temperature distributions of the lower atmosphere derived from GPS/MET data may contribute to the studies of East Asian monsoon and short-term climate variability. Potential applications are:

- Climate monitoring and diagnostics

Routine monitoring of climate variations has been recognized as an important approach to understand the short-term climate variability and the occurrences of abnormal climate condition. Near-real time monitoring of the moisture and temperature derived from GPS/MET 

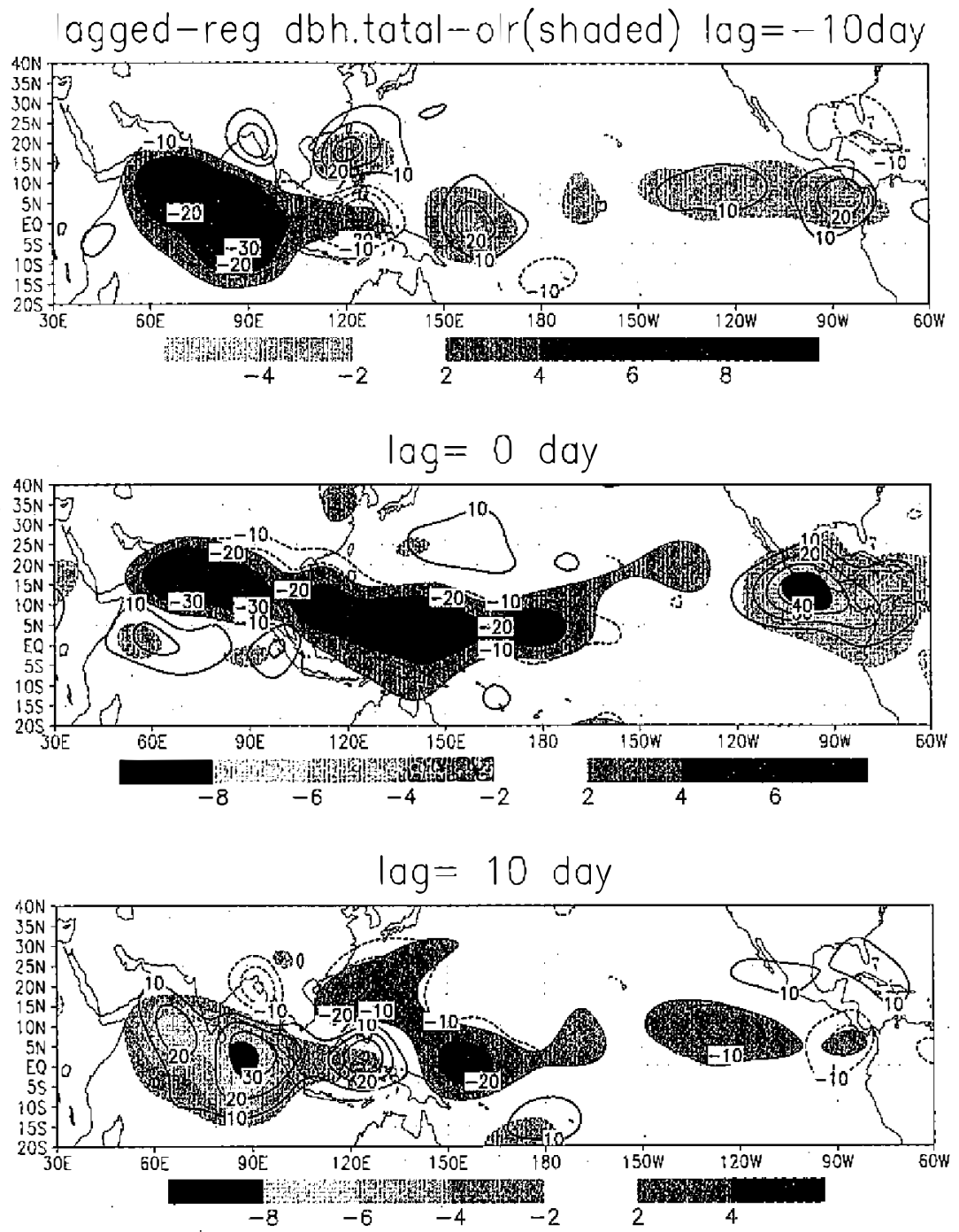

Fig. 5. First singular vector of diabatic heating and outgoing longwave radiation (OLR) fields is shown in the form of regression coefficient to demonstrate the evolution of intraseasonal oscillation in boreal summer from 10 day to 10 day. The heating field shown here is the vertically integrated diabatic heating from surface to $10 \mathrm{hPa}$ based on the ECMWF reanalysis. Both data sets were 30-60 day band pass filtered. Contoured line and shading represent diabatic heating (interval $10 \mathrm{Wm}^{-2}$ ) and outgoing longwave radiation (interval $2 \mathrm{Wm}^{-2}$ ), respectively. Northward and eastward propagation of convection that modulates the variation of Asian summer monsoon can be clearly seen. The diabatic heating field, which is dominated by latent heat release, demonstrates the importance of moisture in the intraseasonal oscillation. 
data can certainly benefit the study of East Asian climate. GPS/MET data can also be used to diagnose the variability of East Asian climate in various time scales and may lead to better understanding of the underlying physical mechanisms.

- Moisture and heat budgets

Water vapor and temperature data can be used to study the 4-D distribution and transportation of water vapor and heat in East Asian monsoon. With other measurements, they may lead to a better understanding of sinks, sources, and budget of moisture and heat. From the standpoint of climate and monsoon studies, the usefulness of the GPS/MET hinges on its ability to provide accurate moisture information in the lower troposphere, as well as good temperature data in the upper troposphere. Since information on tropopause may reflect both the ensemble behavior of deep convection and other internal dynamics within the troposphere, the monitoring of tropopause from GPS/MET data can also be an important application of COSMIC. Having good wind data w'ould be an important addition to the COSMIC data. This is necessary in order to describe properly the low-level moisture convergence, which can serve as the major triggering mechanism for convection, and in turn plays an important role in the development of tropical circulation as well as the maintenance of the monsoon system. A number of satellite missions with wind measurement capability are being planned in the U.S. By coupling COSMIC data with other satellite measurements, this offers an opportunity to make important progress in this area of research.

\section{- Intercomparison study}

Moisture and temperature fields are routinely observed, derived and generated through various approaches such as traditional sounding, satellite and data assimilation. The major difficulties we face are the quality and the availability of the present moisture data. The reanalysis data may provide a new resource for the study. However, these data are strongly affected by the different 4-D assimilation systems and thus exhibit significant differences among themselves, especially for some derived quantities (Higgins et al., 1996; J. Slingo, personal communication). Satellite retrievals, such as NASA Water Vapor Project (NVAP), Global Precipitation Climatology Project (GPCP) and International Satellite Cloud Climatology Project (ISCCP) data, provide independent and valuable information. However, the vertical resolutions of these data are relatively poor. Systematic differences among various retrievals are also significant. The strength of the proposed GPS/MET is to provide moisture and temperature data in a much higher vertical resolution, although the horizontal resolution is still poor. Detailed intercomparison between the GPS/MET data and other data sources should be performed to demonstrate the usefulness of GPS/MET data.

- Model validation

Climate simulation is an important approach for understanding the dynamics and physical processes of a climate system. However, most general circulation and regional models do not treat moisture adequately. Therefore, validation data are needed to diagnose the systematic bias of the moisture field in models and to provide information for further model improvement. GPS/MET data can certainly serve this purpose. 


\section{IMPORTANT ISSUES REGARDING THE APPLICATION OF THE GPS/MET DATA TO THE METEOROLOGICAL RESEARCH AND OPERATION IN TAIWAN}

Understanding the background of GPS/MET, and knowing the problems associated with the weather and climate research conducted in Taiwan, it is important to ask what the meteorological community in Taiwan should prepare now and do in the future to take full advantage of the GPS/MET data for further scientific research. In this section, in part based on the summary from the "COSMIC Science Workshop" (Kuo et al., 1998), some preliminary considerations on how GPS/MET data can be used to enhance weather research and prediction in the Taiwan area are presented. Necessary research work that has to be done prior to the launch of COSMIC satellites is also discussed. The roles of the operational center (CWB) and other research institutes and universities in Taiwan and their main research foci are shown in a schematic diagram (Fig. 6), as discussed in the following.

(1) The role of CWB

(i) COSMIC Data Center

As the sole well-equipped operational meteorological center, as well as the NWP center

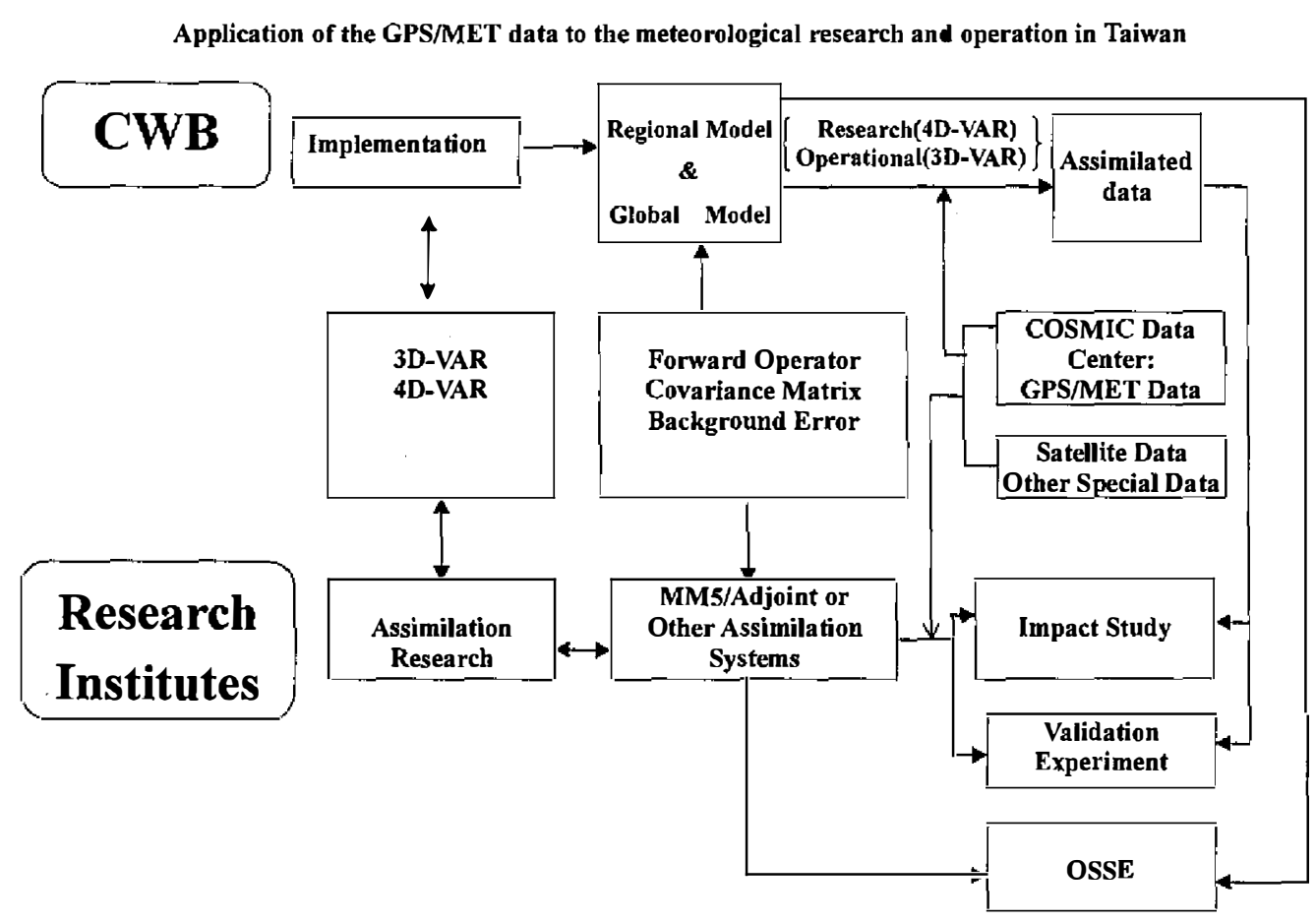

Fig. 6. A schematic diagram indicating the relation of the important issues regarding the application of the GPS/MET data to the meteorological research and operation in Taiwan. 
in Taiwan, the CWB can serve as the COSMIC data center for the Taiwan area for receiving (from UCAR), distributing and archiving the COSMIC data at different levels of processing, including bending angles, refractivity, and temperature, moisture and pressure retrievals. The CWB could also collaborate with scientists and engineers from the U.S. (e.g., UCAR) to develop the data quality control procedures of the data flow.

(ii) Semi-operational data assimilation of GPS/MET data

The CWB can assimilate the GPS/MET data into its global/regional model to provide special analyses that contain the GPS/MET data on a semi-operational-testing basis. With the continuous radio occultation data flowing down from COSMIC satellites, advanced three- or four-dimensional variational data assimilation system (3DVAR/4DVAR) should be used for operational NWP to extract the maximum information from the GPS/MET data. Therefore, the CWB should start developing 3DVAR/4DVAR systems for assimilation of GPS/MET data on both regional and global scales, including all the necessary observational and background error covariances.

With the need to meet the time constraint for the GPS/MET data assimilation semi-operationally, an efficient 3DVAR/4DVAR code needs to be programmed, and powerful computing facility is required. Since the development and testing of various components of a 3DVAR/ 4DVAR system is time consuming, the CWB should start developing its 3DVAR/4DVAR system now so as to take full advantage of the COSMIC data. With this strategy, as indicated in Fig. 6, the CWB can assimilate the GPS/MET data into the 3DVAR system semi-operationally and into the 4D VAR system on an off-line research basis when the COSMIC data become available in 2004 .

(2) Research topics of other research institutes and universities'

(i) Data assimilation research

It should be noted that COSMIC is not a "lone" global observational system. Rather, it is a significant complement to the current global weather observing system, which consists of the traditional surface and upper-air observing networks, and various types of remote sensing observations. Data assimilation schemes need to be developed to couple and integrate GPS/ MET data with various types of remote sensing observations (such as the satellite microwave radiance measurements, precipitable water, rainfall rate, cloud-track winds, and water vapor winds).

The development of an advanced data assimilation system requires a considerable amount of effort. For example, a 4DVAR system includes a forward forecast model, its full-physics adjoint, minimization software, various observational operators (one for each type of observation), model error statistics (background error covariance), and observational error statistics (observational error covariance). Scientists from the research communities in Taiwan need to collaborate with the CWB to advance data assimilation research along this line.

(ii) Evaluation of the impact of COSMIC data on operational NWP and to assess the added value relative to other datasets 
Common practice at operational centers requires extensive testing before a new data source is used for operational implementation. This includes OSSE and semi-operational testing in parallel with the operational runs, as suggested above (also see Fig. 6). A large number of OSSE needs to be conducted to demonstrate the added value of the COSMIC GPS/MET data relative to the current global observing system. For example, work is under way to study how the refractivity information from GPS/MET data can affect the simulation of a typhoon using the MM5 adjoint system currently available.

The OSSE is a challenging task because one needs to develop a data assimilation system that can make effective use of all other types of data in addition to the GPS/MET data. Each data type will require a different observational operator. Moreover, in order to eliminate the problem of "identical twin," which gives overly optimistic results when the same model is used to generate the "simulated" observations and to assimilate the "simulated data" into the model, two or more models need to be utilized for such an exercise. Scientists in Taiwan have started collaborations with both research and operational modeling communities (e.g., NCEP and NCAR) in the U.S. on related issues.

\section{(3) Validation experiment}

A COSMIC validation experiment has been considered during the initial in-orbit operations. This time period provides an excellent opportunity to conduct mesoscale meteorological field programs at low, middle, and high latitudes, and inside and outside of clouds and precipitation. One candidate opportunity is a Mei-Yu or typhoon experiment in the western Pacific and Taiwan area.

During the initial in-orbit operation, radio occultations will take place in close proximity, and therefore, provide high spatial resolution. This offers an opportunity to examine the ability of high-resolution GPS/MET data to describ various types of mesoscale weather systems (including fronts, cyclones, mesoscale convective systems, and typhoons), and to study the potential impact of a constellation with a much larger number of LEO satellites. This also offers a unique opportunity to assess the accuracy of the GPS/MET radio occultation data. Given the fact that satellite orbits can be predicted weeks in advance, field experiments can be designed to validate the GPS/MET soundings. For example, research aircraft can fly along the perigee points of a GPS occultation, and take in-situ measurement for a direct comparison with the GPS/MET data. COSMIC should collaborate with the meteorological community and take part in various "field programs of opportunity" during this period, by making the COSMIC data available in close to real-time. The meteorological community in Taiwan is considering a Mei-Yu and/or typhoon experiment around this time frame. An around-theisland Doppler radar network will be established before the launch of the COSMIC satellites, and the meteorological community in Taiwan will be ready to perform such an experiment. The most likely time for such an experiment will be between May and October in 2004.

\section{SUMMARY}

Meteorological research in Taiwan mainly includes the East Asian climate, the heavy 
rainfall system (Mei-Yu front) and the typhoon research. In this paper, research activities related to these problems in Taiwan have been reviewed. The potential impact of the COSMIC program has also been discussed. It is emphasized that accurate profiles of temperature and water vapor in the troposphere are essential for the meteorological research in Taiwan. Low-level moisture convergence is an important triggering mechanism for convection, whose heating plays important roles in the development of tropical circulation, as well as the maintenance of the monsoon system. Moisture convergence also contributes to the formation and maintenance of the heavy rainfall event in the Mei-Yu frontal system. To improve quantitative precipitation forecasting, better information on the moisture content is necessary. For an accurate typhoon track and intensity prediction, an accurate analysis of atmospheric flow field as well as an accurate representation of heating profile in the typhoon model is required. This means better data on the wind, the temperature and, in particularly, the moisture field are needed for improved research. With the potential for providing useful temperature and moisture information, the data from COSMIC will offer an excellent opportunity for meteorological research in Taiwan. In particular, high-vertical-resolution GPS/MET data from the upper troposphere can be beneficial for studying the tropopause dynamics, which strongly affect the behavior of East Asian climate, the heavy rainfall system and typhoons.

The COSMIC data are expected to provide over 4,000 refractivity and bending angle soundings with uniform global coverage and high refresh rate (about 100 minutes) on a daily basis. Such datasets will be extremely valuable for both regional and global scale NWP, for some data-sparse regions of the world in particular. The fact that the COSMIC data do not require calibration also offers a unique opportunity for the climate community to study subtle and important climate changes at a much higher accuracy than the current global observing system, which does not offer a uniform global coverage and is affected by changes in observing system.

There is some potential in using GPS/MET data for improving weather and climate research in Taiwan. However, significant research is required to assess this potential in detail and to develop capabilities to derive maximum benefit from the GPS/MET data for meteorological research in Taiwan. Extensive studies are also needed to evaluate the relative strength of the GPS/MET data compared to other data currently available, and to determine how the GPS/MET data can most effectively be processed in combination with other data resources and assimilated into the weather prediction models. For these reasons, studies need to be actively carried out in order to take full advantage of COSMIC data once they become available.

It is imperative to develop advanced 3DVAR/4DVAR systems for assimilation of GPS/ MET data on both regional and global scales. The assimilation schemes should also incorporate the GPS/MET data with other types of remote sensing observations, as well as with other conventional observations. The observational and background error covariances need to be evaluated beforehand. A large number of observing system simulation experiments need to be conducted to assess the added value of the COSMIC data. It will be intriguing to conduct a field experiment during the Mei-Yu or typhoon season to validate the GPS/MET soundings during the initial in-orbit operations of COSMIC. Finally, it is crucial to set up a well-equipped COSMIC data center in Taiwan. With all the above efforts, it is hoped that the COSMIC 
program can make a significant contribution to the weather and climate research conducted in Taiwan.

Acknowledgments The authors would like to thank Dr. Ying-Hwa Kuo for his valuable comments and for providing useful information on COSMIC. We also thank Drs. L. Lee, Ching-Yuang Huang, Ming-Deng Cheng, Jen-Chen Chang, Yuan-An Liou, and Chuen-Teyr Terng for helpful discussions in setting up the meteorological research program related to COSMIC. The first author is partially supported through the National Science Council of Taiwan by Grant NSC-88-NSPO(B)-RS3-FA01-01.

\section{REFERENCE}

Anthes, R. A., C. Rocken, and Y.-H. Kuo, 2000: Application of COSMIC to Meteorology and Climate. TAO, 11, 115-156.

Bender, M. A., R. E. Tuleya, and Y. Kurihara, 1987: A numerical study of the effect of island terrain on tropical cyclones. Mon. Wea. Rev., 115, 130-155.

, M. A., C.-C. Wu, M. A. Rennick, and Y. Kurihara, 1997: Comparison of the GFDL hurricane model prediction in the western Pacific using the NOGAPS and AVN global analysis. Proc., 22nd Conference on Hurricanes and Tropical Meteorology. American Meteorological Society, Boston MA. 615-616.

Businger, S., S. R. Chriswell, M. Bevis, J. Duan, R. A. Anthes, C. Rocken, R. Ware, T. Van Hove, and F. Solheim, 1996: The promise of GPS in atmospheric monitoring. Bull. Amer. Meteor. Soc., 77, 5-18.

Chang, C.-P., S. C. Hou, H. C. Kuo, and G. T. J. Chen, 1998: The development of an intense East Asian summer monsoon disturbance with strong vertical coupling. Mon. Wea. Rev., 126, 2692-2712.

Chang, S. W., 1982: The orographic effects induced by an island mountain range on propagating tropical cyclones. Mon. Wea. Rev., 110, 1255-1270.

Chen, C. S., W.-S. Chen, and Z. Deng, 1991: A study of mountain-generated precipitated systems in northem Taiwan during TAMEX IOP\#8. Mon. Wea. Rev., 120, 2574-2606.

Chen, G. T. J., and C. P. Chang, 1980: The structure and vorticity budget of an early summer monsoon trough (Mei-Yu) over southeastern China and Japan. Mon. Wea. Rev., 108, 942-953.

, and J. S. Yang, 1988: On the spatial and temporal patterns of heavy rainfall in Taiwan Mei-Yu season. Atmospheric Sciences, 16, 151-162. (in Chinese with an English abstract.)

1992: Mesoscale features observed in the Taiwan Mei-Yu season. J. Meteor. Soc. Japan, 70, 497-516.

, and C.Y. Liang, 1992: A midlevel vortex observed in TAMEX. J. Meteor. Soc. Japan, 70, 25-41.

Chen, M.-S., and J.-T. Wang, 1998: The evolution of large-scale pattern during the onset of East Asian summer monsoon. Atmospheric Sciences, 26, 109-131. (in Chinese with an English abstract.) 
Chen, Y. L., and J. Li, 1995: Characteristics of surface airflow and pressure patterns over the island of Taiwan during TAMEX. Mon. Wea. Rev., 123, 2978-3002.

Davis, C. A., and K. A. Emanuel, 1991: Potential vorticity diagnostics of cyclogenesis. Mon. Wea. Rev., 119, 1929-1953.

Emanuel, K., and R. Landland, 1998: FASTEX adaptive observations workshop. Bull. Amer. Meteor. Soc., 79, 1915-1919.

Eyre, J., 1994: Assimilation of radio occultation measurements into a numerical weather prediction system, Tech. Memo.199, Eur. Cent. For Medium Range Weather Forecasts, Reading, England.

Franklin, J. L., S. E. Feuer, J. Kaplan, and S. D. Aberson, 1996: Tropical cyclone motion and surrounding flow relations: Searching for beta gyres in Omega Dropwindsonde Datasets. Mon. Wea. Rev., 124, 64-84.

Higgins, R. W., Y.-P. Yao, M. Chelliah, W. Ebisuzaki, J. E. Janowiak, C. F. Ropelewski, and R. E. Kistler, 1996: Intercomparison of the NCEP/NCAR and the NASA/DAO Reanalyses (1985-1993). NCEP/Climate Prediction Center ATLAS No. 2, 169pp.

Holland, G. J., T. McGeer, and H. Youngren, 1992: Autonomous aerosondes for economical atmospheric sounding anywhere on the globe. Bull. Amer: Meteor. Soc., 73, 1987-1998.

Hsu, H.-H., M.-F. Wang, and C.-P. Wang, 1997: Atlas of Global Atmospheric Circulation: ECMWF analysis, 1985-1995. Data Bank for Atmospheric Research. (in Chinese with an English abstract.)

, C.-T. Terng, and C.-T. Chen, 1999: Evolution of large-scale circulation and heating during the first transition of Asian summer monsoon. J. Climate, 12, 793-810.

Hsu, W. R., and W. Y. Sun, 1994: A numerical study of low-level jet and its accompanying secondary circulation in a Mei-Yu system. Mon. Wea. Rev., 122, 324-340.

Hwu, J.-W., and J.-T. Wang, 1994: Spring time East Asia large scale characteristics post ENSO. Part II: The circulation pattern of different levels. Atmospheric Sciences, 22, 360-386. (in Chinese with an English abstract.)

Johnson, R. H., and J. F. Bresch, 1991: Diagnosed characteristics of Mei-Yu precipitation systems over Taiwan during the May-June 1987 TAMEX.Mon. Wea. Rev., 119, 25402557.

Jou, B. J.-D., and S. M. Deng, 1992: Structure of a low-level jet and its role in triggering and organizing moist convection over Taiwan: A TAMEX case study. TAO, 3, 39-58. , 1997: Heavy rainfall research in Taiwan area: Project Office (III). Technical report, National Science Council, 347pp. (In Chinese with an English abstract.)

, J. S. Hong, and D. N. Lin, 1999: A numerical study of the mesoscale convective systems formed along the Mei-Yu front during MYEX98. Preprints, 6th National Conference on Atmospheric Sciences, Taipei, 46-53. (In Chinese with an English Abstract.)

Kau, W.-S. and B.-Y. Deng, 1994: The evolution of South Asia upper anticyclone and the precipitation in early Mei-Yu season. Atmospheric Sciences, 22, 129-162. (in Chinese with an English abstract.)

, H.-H. Hsu, A. N. Shei, and K. N. Liou, 1995: The NTU atmospheric general circulation model. NTU Technical Report, 95pp.

, 1998: The NTUGCM's simulation on the East Asian summer monsoon. TAO, 9, 197- 
238.

Krishnan, R., and C. Venkatesan, 1997: Mechanisms of low frequency intraseasonal oscillations of the Indian summer monsoon. Meteor. Atmos. Phys., 62, 101-128.

Kuo, Y.-H., and G. T. J. Chen, 1990: Taiwan Area Mesoscale Experiment: An overview. Bull. Amer. Meteor. Soc. 71, 488-505.

, X. Zou, and Y. R. Guo, 1996: Variational assimilation of precipitable water using a nonhydrostatic mesoscale adjoint model, Part I: Moisture retrieval and sensitivity experiments. Mon. Wea. Rev., 124, 122-147.

, and W. Huang, 1997: The impact of GPS data on the prediction of an extratropical cyclone: An observing system simulation experiment. J. Dyna. Atmos. Ocean, Guest Editors: I. M. Navon, E. Kalnay, and P. H. Stone, 27, 413-439.

, S.-J. Chen, W. Huang, Y.-R. Guo, R. A. Anthes, M. Exner, D. Hunt, C. Rocken, and S. Sokolovskiy, 1998: A GPS/MET sounding through an intense upper-level front. Bull. Amer. Meteor. Soc. 79, 617-626.

, C. Rocken, B. Chao, M.-D. Cheng, G. Hajj, L. Lee, C.-H. Liu, J. North, Y.-B. Tsai, and T. Yunck, 1998: U.S.-Taiwan Bilateral COSMIC Science Workshop. Summary of Working Group Reports, 20pp.

Kurihara, Y., M. A. Bender, R. E. Tuleya, and R. J. Ross, 1995: Improvements in the GFDL hurricane prediction system. Mon. Wea. Rev., 123, 2791-2801.

Langford, J. S., and K. A. Emanuel, 1993: An unmanned aircraft for dropwindsonde development and hurricane reconnaissance. Bull. Amer. Meteor. Soc., 74, 367-375.

Lau, K. M., and L. Peng, 1990: Origin of low frequency (intraseasonal) oscillations in the tropical atmosphere. Part III: Monsoon dynamics. J. Atmos. Sci., 47, 1443-1462.

Lin, P.-H., and LinHo, 1997: The Asian summer monsoon and Mei-Yu front. Part I: Cloud pattern as a monsoon index. Atmospheric Sciences, 25, 267-288. (in Chinese with an English abstract.)

Lin, Y.-L., 1993: Orographic effects on airflow and mesoscale weather systems over Taiwan. TAO, 4, 381-420.

Lin, Y.-J., R. W. Pasken, and H.W. Chang, 1992: The structure of a subtropical prefrontal convective rainband. Part I: Mesoscale kinematic structure determined from dual-Doppler measurements. Mon. Wea. Rev., 120, 1816-1836.

Lu, M.-M., 1998: A study on the relationship of the onset dates of the South China Sea summer monsoon and Taiwan precipitation in the Mei-Yu season. Atmospheric Sciences, 26, 205-225. (in Chinese with an English abstract.)

Marks, F. D., R. A. Houze, and J. F. Gamache, 1992: Dual-air-craft investigation of the inner core of Hurricane Norbert. Part I: Kinematic structure. J. Atmos. Sci., 49, 919-942.

Merrill, R. T., and C. S. Velden, 1996 : A three-dimensional analysis of outflow layer of Supertyphoon Flo ( 1990 ). Mon. Wea. Rev., 124, 47-63.

Morgan, M.C., and J. W. Nielsen-Gammon, 1998: Using tropopause maps to diagnose midlatitude weather systems. Mon. Wea. Rev., 126, 2555-2579.

Pan, C., and J.-T. Wang, 1996: A study on the East Asian summer monsoon interannual variability: Viewpoints from different region. Atmospheric Sciences, 24, 89-122. (in Chinese with an English abstract.) 
Rocken, C., T. VanHove, J. Johnson, F. Solheim, R. H. Ware, M. Bevis, S. Businger, and S. R. Chiswell, 1995: GPS/STORM-GPS sensing of atmospheric water vapor for meteorology. J. Atmos. Oceanic Technol., 12, 468-478.

Shieh, S.-L, S.-T. Wang, M.-D. Cheng, and T.-C. Yeh, 1996: User's guide (1) for typhoon forecasting in the Taiwan area. Res. Rep. CWB84-1M-01, 356 pp. (in Chinese with an English abstract.)

Sun, W. Y., J. D. Chern, W. R. Hsu, and C. C. Wu, 1991: Numerical simulation of mesoscale circulation in Taiwan and surrounding area. Mon. Wea. Rev., 119, 2558-2573.

Tao, S. and L. Chen, 1987: A review of recent research on the East Asian summer monsoon in China. In "Monsoon Meteorology", C.-P. Chang and T. N. Krishnamurti eds., Oxford University Press, 60-92.

Trier, S. B., D. B. Parsons, and T.J. Matejka, 1990: Observations of a subtropical cold front in a region of complex terrain. Mon. Wea. Rev., 118, 2449-2470.

Wang, B., and X. Xie, 1997: A model for the boreal summer intraseasonal oscillation. $J$. Atmos. Sci., 54, 72-86.

Wang, J.-T., C.M. Huang, and J.-W. Hwu, 1992: The circulation characteristics during anomalous Mei-Yu seasons. Atmsopheric Sciences, 20, 267-294. (in Chinese with an English abstract.) , and J.-W. Hwu, 1994: Spring time East Asia large scale characteristics post ENSO. Part I: The spatial distribution of SST and OLR. Atmospheric Sciences, 22, 339-360. (in Chinese with an English abstract.)

Wang, S.-T., 1980: Prediction of the behavior and strength of typhoons in Taiwan and its vicinity. Res. Rep. 108, National Science Council, Taipei, Taiwan, 100 pp. (in Chinese.)

Ware, R., and Co-authors, 1996: GPS sounding of the atmosphere from low Earth orbit: Preliminary results. Bull. Amer. Meteor. Soc., 77, 19-40.

Webster, P. J., 1983: Mechanisms of monsoon low-frequency variability: Surface hydrological effects. J. Atmos. Sci., 40, 2110-2124.

Wu, C.-C., and K. A. Emanuel, 1993: Interaction of a baroclinic vortex with background shear: Application to hurricane movement. J. Atmos. Sci., 50, 62-76. , and 1995: Potential vorticity diagnostics of hurricane movement. Part I: A case study of Hurricane Bob (1991). Mon. Wea. Rev., 123, 69-92. , and Y. Kurihara, 1996: A numerical study of the feedback mechanisms of hurricaneenvironment interaction on hurricane movement from the potential vorticity perspective. J. Atmos. Sci., 53, 2264-2282.

, and Y.-H. Kuo, 1999: Typhoons affecting Taiwan: Current understanding and future challenges. Bull. Ameri. Meteor. Soc., 80, 67-80.

Yeh, T.-C., and R. L. Elsberry, 1993a: Interaction of typhoons with the Taiwan orography. Part I. Upstream track deflections. Mon. Wea. Rev., 121, 3193-3212.

Yeh, T.-C., and R. L. Elsberry, 1993b: Interaction of typhoons with the Taiwan orography. Part II. Continuous and discontinuous tracks across the island. Mon. Wea. Rev., 121, 3213-3233.

Yu, C. K., B. J.-D. Jou, and B. F. Smull, 1999: Formative stage of a long-lived mesoscale 
vortex observed by airborne Doppler radar. Mon. Wea. Rev., 127, 838-857.

Zou, X., F. Vandenberghe, B. Wang, M. E. Gorbunov, Y.-H. Kuo, S. Sokolovskiy, J. C. Chang, J. G. Sela, and R. A. Anthes, 1999: A ray-tracing operator and its adjoint for the use of GPS/MET refraction angle measurements. J. Geophys. Res., 104, D18, 2230122318.

Zou, X., B. Wang, H. Liu, R. A. Anthes, T. Matsumura, and Y.-J. Zhu, 2000: Use of GPS/ MET refraction angles in 3D variational analysis. Quart. J. Roy. Meteor. Soc., (in press). 